Lucio R. Renno

\title{
O saldo da crise democrática na América Latina: sobre a legitimidade e a consolidação da Democracia Representativa ${ }^{1}$
}

\section{Introdução}

A Democracia na América Latina encontra-se numa encruzilhada sem precedentes: democracia representativa - sustentada por eleições livres e justas, competição multipartidária, estado de direito e um sistema de pesos e contrapesos - tem sido desafiada por uma visão mais radical de democracia direta, com base em consultas populares constantes, na redução da competição entre elites e na centralização do poder político no Executivo. A particularidade da atual junção crítica na história de região é que os desafios acerca do regime democrático nascem de eleições: são, portanto, provenientes de dentro do próprio sistema. Isto é, líderes eleitos diretamente pelos mecanismos de democracia representativa conduzem as reformas radicais correntes que podem minar o próprio modelo Madisoniano de democracia, baseado na representação política e no sistema de checks and balances, que existem atualmente na maioria dos países latino-americanos. Assim, argumento aqui que a nova forma de instabilidade política na América Latina, ao contrário do que pensam alguns, pode sim estar afetando a própria continuidade do regime democrático na região (Perez-Liñan 2007, 2008; Llanos/Marsteintredet 2010). Dessa forma, o atual processo de mudança de regime e instabilidade na América Latina apóiase na erosão da democracia representativa e não apenas quedas de presidentes

${ }^{1}$ Uma versão inicial deste artigo foi escrita durante residência no Latin American Centre (LAC) da University of Oxford, com apoio do Researcher Exchange Program Conselho Britânico. Agradeço a Timothy Power, aos colegas e aos estudantes do LAC pelos comentários e sugestões. Também agradeço a comentários de colegas em apresentação do paper no Encontro de Potsdam, Alemanha do European Corsortium for Political Research (ECPR). Agradeço ainda a Anthony Spanakos pelas sugestões e, finalmente, ao apoio da Fundação de Apoio a Pesquisa do Distrito Federal - FAP/DF - pela assistência financeira que viabilizou a participação no encontro ECPR. Equívocos restantes no texto são de minha responsabilidade. 
através de renúncias e impeachments. Há em curso uma intensificação das crises da democracia na região (Boniface 2007), motivadas por crises prolongadas das instituições de representação democrática (Mainwaring 2006).

Além disso, e mais importante, em alguns países, esses embates tem resultado em mudanças institucionais que mexem no cerne dos princípios democráticos representativos, ampliando cada vez mais os mecanismos participativos e centralizando a convocação desses mecanismos no poder executivo. Este processo de erosão dos componentes representativos pode ser, em grande parte, sustentado pela frustração popular com a ausência de justiça social, inclusão econômica e participação popular direta no processo de tomada de decisão que prevaleceu no continente durante a chamada era "neoliberal" (Hochstetler 2008, Hochstetler/Edwards 2009). Ou seja, a insatisfação presente pode ser resultado de avaliações negativas da qualidade da democracia na região (Rennó et al. 2011).

Como consequência, há a oportunidade na América Latina de hoje de algo que era impensável há alguns anos e que Przeworski denominou de "mandato eleitoral para o socialismo" (1986: 60). ${ }^{2}$ Como consequência de uma generalizada frustração com o processo de enxugamento do Estado e aumento da informalidade na economia na década de noventa (Hoffman/Centeno 2003, Portes/Hoffman 2003), o apelo inclusivo da retórica corrente é muito atraente para as parcelas excluídas da população e para ideólogos de esquerda. Não apenas isto, está relacionado também com limitações existentes no funcionamento das democracias representativas na América Latina. Deste modo, a discussão acerca da qualidade da democracia é central para entender o surgimento de uma visão crítica sobre o regime e sobre desafios aos seus princípios básicos. ${ }^{3}$

Estas mudanças, naturalmente, encontram resistência das elites tradicionais e daqueles preocupados com a aproximação desses novos regimes com o populismo e socialismo, assim como com a queda das características constitucionais liberais que marcaram a democracia na América Latina (Zakaria 1996, Seligson 2007). Esses grupos,novamente em alguns países, tem reagido de forma contundente aos processos de reforma institucional implantadas após as crises. $\mathrm{O}$ resultado dessa situação é um aumento na instabilidade política, no conflito e na violência política na região e recorrentes impasses e crises constitucionais.

Mas, quais são esses países que claramente atravessaram crises e impasses políticos recentes e posteriormente embarcaram em processos de mudança

2 Venezuela é o principal exemplo.

3 Para uma discussão sobre qualidade da democracia, veja Diamond and Morlino (2004). Para sua aplicação ao caso brasileiro, veja Rennó et al. (2011). 
constitucional que alteram a ordem democrática? Venezuela, Equador e Bolívia - com violência generalizada pelas ruas, sérios desafios impostos aos governos por forças de oposição e questionamento consistente das reformas de governo - são paradigmas desta nova situação de instabilidade na região.

A recente literatura sobre novas formas de instabilidade na América Latina tem oferecido uma extensa lista de presidentes fracassados - Equador e Paraguai, mais recentemente, mas também Argentina, são os grandes exemplos que integram esta nova dinâmica de instabilidade política (Perez-Liñan 2007, 2008, Llanos/Marsteintredet 2010). Se levarmos em consideração também os constantes questionamentos de resultados eleitorais, o aumento da incidência de protestos políticos e manifestações de rua, esses episódios de instabilidade podem também indicar um novo processo de turbulência política regional com sérias implicações para o funcionamento da democracia. Desta forma, contrariando a literatura sobre novas formas de instabilidade política que afirma que as crises atuais não levam à mudanças no regime, acontecimentos recentes em alguns países da América Latina permitem-nos especular que mudanças no regime não devem ser totalmente descartadas dentre as possíveis consequências das crises. Ou seja, o saldo das crises democráticas pode resvalar em alterações na ordem institucional e claramente condicionar as formas como os cidadãos desses países pensam sobre seus regimes, principalmente em contraste com países que não atravessaram tais crises.

Ao listar os eventos desta natureza ocorridos nas últimas duas décadas (até 2007), Boniface define crise como a "interrupção repentina ou irregular do processo institucional político-democrático", conforme definido na Resolução 1080 da Organização dos Estados Americanos (OEA), e qualquer "alteração inconstitucional da constituição (...) que seriamente debilite a ordem democrática”, como indica a Carta Democrática de 2001 da OEA (Boniface 2007, 46-47). Seguindo esse critério, Boniface identifica 19 episódios de crise constitucional na América Latina entre 1991 e 2007. Cinco referem-se a golpes de Estado ou auto-golpes - Haiti (1991), Peru (1992), Guatemala (1993), Equador (2000) e Venezuela (2002) e um caso de ameaça militar de retirada de um presidente antes do termino de seu mandato: Paraguai em 1996. Outro grupo de casos Paraguai (1999/2000), Bolívia (2003), Haiti (2004) e Equador (2004/2005) "ocupam uma área cinzenta" porque eles envolvem violência, renúncias de presidentes e acusações de golpes, mas não tão claramente quanto os primeiros seis casos. Os nove casos restantes são vistos como exemplos de falhas em eleições majoritárias ou impasses constitucionais. Eles incluem República Dominicana (1994), Equador (1997), Haiti (2000/2003), Peru (2000), Argentina (2001), Trinidad e Tobago (2000/2001), Bolívia (2005) e Nicarágua (2001/2005).

Estes dados indicam que alguns países na América Latina são mais propensos a episódios de instabilidade que outros. Portanto, a América Latina 
atual pode ser dividida em dois grandes grupos de casos: países que têm enfrentado turbulência política radical na última década e países que não enfrentaram tais situações. Assim sendo, surgem duas perguntas. A primeira seria por que um grupo de países sofre um tipo ou outro de crise enquanto outros não? Existem traços comuns ou padrões entre os distintos grupos? A segunda pergunta seria quais são as consequências desses golpes para os grupos sociais desses países? Os cidadãos desses países têm opiniões sobre seus regimes políticos diferentes dos cidadãos de países que não passaram por essas crises?

Nós exploramos aqui o segundo conjunto de perguntas, com foco nas consequências da crise sobre regimes políticos a partir da ótica dos cidadãos e contrastando países que sofreram e os que não sofreram crises democráticas. Esta é portanto uma investigação sobre os efeitos de uma década de crise política na região sobre a opinião pública, que é medida por meio das pesquisas fornecidas pelo Barômetro das Américas de 2008 em todos os países do continente. Não serão exploradas as causas da instabilidade. Este é uma meta para um projeto futuro ${ }^{4}$. Nós começamos pela investigação dos efeitos da crise sobre a perspectiva dos eleitores acerca da legitimidade de seus regimes políticos, fator esse intimamente ligado ao surgimento de rupturas na ordem democrática nos anos 70, como apontou Linz (1978) e que hoje continuam presentes nas preocupações de pesquisadores da região, como Booth/Seligson (2009).

Este artigo procura contrastar as visões de cidadãos de países que atravessaram crises com os que não atravessaram em fatores que são vistos pela literatura especializada como centrais para entendermos processos de instabilidade e quebra do regime democrático: perda de legitimidade, entendido aqui como apoio popular e aquiescência à democracia. Deste modo, o foco é em como indivíduos pensam sobre seus governantes, sobre o regime democrático e acerca de seus problemas cotidianos.

Obviamente, a opinião dos cidadãos sobre regimes políticos não é a única explicação para mudanças de regime. Alinhamentos de elites, desenhos insti-

${ }^{4}$ Boniface indica alguns padrões explicativos para as crises democráticas (2007: 51). Primeiro, as crises tornam-se mais frequentes a partir da chegada ao poder de Hugo Chávez em 1999. Ou seja, há uma dimensão temporal explicando a crise e um evento, o início do período Chávez na Venezuela, que marcam a intensificação da turbulência democrática na América Latina. Uma segunda dimensão é geográfica e reforça a dimensão temporal. Grande parte das crises ocorre em países da região andina. Finalmente, não há claro padrão econômico para a crise: as crises não são privilégio de países mais pobres, já que a Venezuela não faz parte desse grupo na região. Esses insights são interessantes, mas insuficientes para entendermos por que alguns países são vítimas de crise, às vezes consecutivas, e outros não. De qualquer forma, esse é um tema para outra pesquisa e trabalho. 
tucionais, problemas econômicos estruturais e fatores internacionais levam isoladamente ou em conjunto - a instabilidade e queda de um regime político (Przeworski 1986: 50). Portanto, deve ficar claro que o apoio popular, que será discutido posteriormente em detalhe, é necessário mas insuficiente para explicar mudanças de regime. Todavia, as formas como cidadãos e cidadãs pensam sobre seus regimes pode ter impactos relevantes para a estabilidade e o aprofundamento da democracia em sua fase de consolidação (Reis/O'Donnell 1989, Moisés 1995). Assim sendo, a pesquisa sobre apoio e visão popular no que se refere à democracia é uma forma de medir o grau de consolidação da democracia na América Latina.

Além disso, em um momento quando a participação popular se torna um aspecto central de inovação no funcionamento da democracia para os otimistas (Avritzer 2002) ou uma ameaça à democracia representativa para os pessimistas (Mainwaring et al. 2006), é importante entender como os cidadãos percebem os sistemas políticos e a qualidade de seus representantes e servidores públicos.

Em resumo, o objetivo deste trabalho é analisar como a ótica popular sobre corrupção e crime, a performance econômica dos governos, a participação individual em movimentos de protestos e o funcionamento das instituições democráticas diferem entre cidadãos de países que enfrentaram crises democráticas a partir de 1995 dos países que não passaram por tais crises. As crises do início dos anos 90 não devem ter reflexos nas visões atuais dos cidadãos sobre os regimes. A diferença temporal pode ser muito grande e as crises nesses países não levaram à reformas profundas do sistema político. Por esta razão, Guatemala e República Dominicana - presentes na lista de Boniface não são incluídos entre os países que enfrentam crises nesta análise. Portanto, crises democráticas podem ocorrer em qualquer lugar. Algumas podem levar à mudanças radicais na democracia e outras não, mas nenhum regime está imune à crises. Na verdade, a forma de resolução das crises é que passa a ser central sobre o seu saldo, seu impacto no futuro. Pode-se argumentar que o nível de consolidação da democracia é definido por como regimes lidam com suas crises políticas. Desta forma, as consequências da crise se tornam chave para entender as perspectivas para consolidação da democracia.

Eu me baseio na rica literatura sobre legitimidade política, assim como em estudos mais recentes acerca da qualidade da democracia e representação para orientar a análise empírica. Finalmente, emprego pesquisas de opinião pública do Barômetro das Américas de 2008, realizadas em todos os países da América Latina, da América do Norte, além de Haiti, República Dominicana e Jamaica a fim de explorar as perspectivas dos cidadãos sobre os fatores listados anteriormente. Tendo em vista que estudos prévios nesta agenda de pesquisa utilizam dados de 1996, eu atualizarei esses resultados (Mainwaring 2006). 


\section{Legitimidade, Qualidade e Consolidação da Representação democrática}

Juan Linz define legitimidade como "crença que, apesar das limitações e falhas, as instituições políticas existentes são melhores que quaisquer outras que possam ser estabelecidas e, por isso, podem demandar obediência" (1978: 16). Ele sustenta que reações da opinião pública são um indicador indireto de legitimidade, pois são uma reação à atuação de elites políticas que tem desempenhado de forma insatisfatória seu papel representativo. Mainwaring complementa esse raciocínio argumentando que "onde cidadãos comuns não são comprometidos com a democracia, eles estarão abertos à lideres e grupos de 'oposição desleal'” (1992: 307). Tais líderes, que não tem compromisso claro com o regime político democrático, mas prioritariamente com seus próprios projetos de poder, podem gerar amplas ondas de reprovação popular, também frustrada com o desempenho do regime. Por isso, a percepção dos cidadãos sobre o funcionamento do Estado, sobre o desempenho do governo e das instituições políticas se torna central para entender o saldo, as consequências das crises e falhas do regime.

A idéia de legitimidade está intimamente relacionada ao conceito de consolidação democrática, ambas no centro de debates importantes na literatura sobre a transição de regimes. O'Donnell claramente diferencia duas etapas no processo de mudança de regime (O’Donnell 1989). O primeiro é rotulado como transição, que é marcado pela alteração na configuração institucional do regime. Ele começa como um processo de reforma institucional que culmina em uma mudança dramática no sistema político, alterando completamente as regras de como atores políticos interagem e como decisões são tomadas. Um segundo momento é aquele que começa após a conclusão do processo de mudança institucional e foi chamado de "período de consolidação", referindose a como atores políticos incorporam e aceitam a novas regras do jogo. Deste modo, o momento de consolidação é de incorporação e incorporação por parte de todos os atores políticos - do eleitor/cidadão ao representante eleito, incluindo oposição e situação - das práticas e instituições democráticas e da aceitação delas como únicas formas válidas e legítimas de obediência à ordem política. A questão da consolidação da democracia é, consequentemente, uma de forjar a legitimidade do sistema político. Esta questão se refere à como elites e massas vêem seu sistema político, obedecem as regras e apesar de discordarem sobre as direções dos governos, não questionam o regime. Em outras palavras, trata-se de haver apoio latente ao sistema, independentemente de apoio específico, que remete a uma prática de apoiar as instituições e princípios democráticos sem necessariamente deixar de ser crítico dos governantes de plantão (Booth/Seligson 2009). 
Expostas tais afirmações teóricas, o que as atuais crises da democracia na América Latina representam para a legitimidade do regime? Estas crises deixam para trás um legado de instabilidade que influencia como cidadãos pensam sobre seus sistemas políticos e como eles se comportam politicamente? Qual a profundidade das cicatrizes deixadas pelas crises democráticas - se é que elas existem - nas visões, crenças e preferências sobre política? Essas perguntas são sobre política de massa e legitimidade do regime baseada na percepção dos cidadãos. Cidadãos em países que enfrentam crises democráticas recentemente vêem sistemas políticos diferentemente dos cidadãos de outros países?

\section{Algumas hipóteses sobre as consequências das crises democráticas}

Se as cicatrizes das crises democráticas são profundas e se, de fato, deixam um legado, espera-se ver diferenças entre países que enfrentaram crises e aqueles que não. Isto indicaria que a natureza esporádica das crises tem efeito muito mais longo no que se refere à estabilidade do regime do que a literatura corrente imagina. Tal fato traz para o centro da discussão o ponto de que crises malresolvidas são um desafio significativo para a consolidação da democracia em alguns países da América Latina.

Além disso, estas crises podem ser resultantes de uma cadeia de eventos que ligam longos processos históricos de exclusão (Reis/O'Donnell 1989), acentuados pela implementação da agenda neoliberal dos anos 90 (Hagopian 2006). Os episódios de crises democráticas/institucionais analisados aqui sinalizam deficiências do processo de representação democrática, que na perspectiva da opinião pública pode ser aferida como um "desafeto com os veículos convencionais de representação democrática (Mainwaring et al. 2006: 2). Deste modo, as crises nascem de processos profundos de ausência de legitimidade do regime político e que remetem à visão de que as percepções populares sobre o regime precisam ser consideradas na análise de transições e de processo de consolidação.

Estudos recentes têm confirmado estas expectativas. Mainwaring e Hagopian argumentam claramente que "atitudes favoráveis à democracia e um ambiente internacional favorável" são mais importantes para explicar a sobrevivência ou fracasso de um regime competitivo na América Latina do que fatores estruturais" (2005: 7). Hagopian afirma ainda enfaticamente que atitudes sobre a democracia estão relacionadas com expectativas e avaliações da performance do governo e da qualidade da representação. Assim, tópicos como segurança pública, desempenho econômico e corrupção ocupam lugar 
central na avaliação dos cidadãos sobre a performance de seus representantes (Hagopian 2005: 345). Mainwaring et al. argumenta que governança e deficiências do Estado nestas áreas são instrumentos para explicar perdas de legitimidade e instabilidade do regime (2006). Por isso, fatores que afetam adversamente a qualidade de vida (violência, pobreza, desigualdade e corrupção) e que podem ser heranças de um mal desempenho governamental e das fragilidades do Estado na região diminuem a legitimidade das instituições democráticas aos olhos do público. Se Estado e governos não resolvem esses problemas ou não demonstram enfrentá-los, eles viram desafios à sobrevivência do regime. Como mencionado anteriormente, seguindo Linz, problemas mal resolvidos se tornam gatilhos para crises democráticas e rupturas constitucionais futuras (1978).

Portanto, a questão por trás da fragilidade da legitimidade democrática na América Latina é a baixa qualidade do desempenho da democracia representativa em alguns países. Governos sucessivos têm feito pouco para melhorar a qualidade de vida em alguns países da região que criam a base para o crescimento de demandas (e oferta) por reformas radicais. A frustração acumulada com a continuada incapacidade dos governos anteriores de solucionar problemas de exclusão social e pobreza está certamente na raiz das atuais crises democráticas na região, levando ao apoio cada vez maior à formas mais radicais de democracia direta e à frustração com os mecanismos representativos.

Mainwaring testa algumas dessas hipóteses ao analisar os fatores determinantes de confiança nas instituições, sua proxy para legitimidade democrática, em alguns países latino-americanos usando vários indicadores de desempenho do sistema político, tais como visões sobre economia, corrupção e violência (2006). Utilizando dados do Latinobarômetro de 1996, ele conclui que as visões sobre corrupção são centrais para explicar a perda de confiança nas instituições.

Nosso objetivo empírico neste artigo é atualizar a análise realizada por Mainwaring com dados de 2008 e analisar países que enfrentaram crises assim como países que não passaram por crises democráticas na última década. Mainwaring foca exclusivamente em países problemáticos da região andina, tratando apenas de casos onde há crises democráticas. Consequentemente, sua análise sofre de um viés de seleção. Com a incorporação de países que não enfrentaram crises, eu amplio o seu trabalho e comparo os dois grupos de países. Este é um teste crucial para compreender como o legado das crises influencia a legitimidade do regime. Além da confiança nas instituições, também tentamos explicar como outras dimensões da legitimidade democrática se diferenciam entre países que passaram por crises e os demais (Booth/Seligson 2010).

Por último, nós também incorporamos um ingrediente final da receita para crises democráticas: a participação dos cidadãos em movimentos de protesto. Desde os primeiros estudos feitos por Huntington sobre ordem política nas 
sociedades em modernização, a inclinação dos cidadãos ao engajamento em movimentos de protesto e desobediência civil figura nas raízes da instabilidade de regimes políticos (1968). Obviamente, movimentos de protestos estão relacionados com a falta de canais institucionais para intermediação, tais como partidos políticos e com problemas mal resolvidos, dentre os quais desigualdade e pobreza aparecem como principais motivações para protestos. Hochstetler (2008) e Hochstetler/Edwards (2009) claramente apontam a existência de protestos populares como um ingrediente fundamental para a derrubada de presidentes na América Latina. Se as crises têm impacto negativo sobre a legitimidade do regime, espera-se que protestos sejam ainda mais predominantes em países que enfrentaram crises.

Em resumo: combine fraco desempenho governamental, crime, corrupção e fragilidade dos mecanismos de representação institucional, como partidos políticos; misture-os com protestos políticos recorrentes e, voilá, você tem uma mistura explosiva de sabores, mais semelhante a um coquetel Molotov do que propriamente a um milkshake de tardes ensolaradas de domingo. De qualquer forma, a democracia representativa estará sujeita a uma inevitável e dolorida ressaca no dia seguinte.

\section{Dados, hipóteses e variáveis}

Com base nos dados do Barômetro das Américas de 2008, nós testamos a receita acima. A série é coordenada por Mitchell A. Seligson como parte do Latin American Public Opinion Project (LAPOP) da Vanderbilt University. Uma rede ampla de pesquisadores de todas as Américas participa ativamente em todos os estágios do processo de coleta dos dados, da elaboração dos questionários e desenho da amostra ao pré-teste do questionário, culminando com o treinamento dos entrevistadores e uma extensa e profunda supervisão do trabalho de campo, visando a coleta de dados de opinião público da mais alta qualidade. Os questionários contêm módulos idênticos em todos os países, assim como abordam temas específicos à cada país. O trabalho de campo foi sincronizado em quase todos os países, aumentando ainda mais a comparabilidade das respostas dadas pelos entrevistados à nossas perguntas. As amostras são quasi-probabilísticas, com uma quota por gênero e idade dentro do domicílio, e em estágios múltiplos completamente aleatórios até a seleção do domicílio. Os tamanhos das amostras não variam consideravelmente (+/- 1500 por país) e são pesadas para assegurarem igualdade nos resultados quando analisadas simultaneamente.

A análise dos dados procederá em dois estágios. Inicialmente, o foco é na comparação entre países que enfrentaram crises na década passada e àqueles 
que não enfrentaram através de variáveis chaves propostas aqui. Em seguida iremos explorar simples medidas de associação entre ter vivido em países em crise e visões sobre diversas variáveis que são tidas como chave na descrição das raízes das novas formas de instabilidade política na região.

Assim, serão analisadas as avaliações declaradas dos cidadãos em relação ao desempenho econômico do governo, suas experiências de corrupção e crime, a sua participação em protestos políticos e às formas distintas de avaliação e comprometimento institucional. Argumenta-se que as perspectivas dos cidadãos sobre essas questões serão mais negativas em países que enfrentam turbulência política recorrente: Haiti, Nicarágua, Equador, Venezuela, Paraguai, Peru e Bolívia. Sobretudo, nossas hipóteses são que cidadãos que vivem em países que passaram por crises democráticas são mais inclinados a:

1) Avaliar negativamente o desempenho econômico dos governos;

2) Apresentar maior vitimização e percepção sobre corrupção;

3) Ter sido vítima de crimes com mais frequência;

4) Ter participado de protestos políticos com mais frequência;

5) Demonstrar baixos níveis de identificação e confiança em partidos políticos;

6) Avaliar negativamente seus representantes no Congresso;

7) Apresentar baixos níveis de confiança nas principais instituições políticas; (Sistema Judiciário, Congresso, Suprema Corte e Governo Nacional).

A fim de operacionar os conceitos mencionados acima, nós aplicamos os seguintes itens encontrados no Barômetro das Américas.

Desempenho econômico governamental é um índice somatório de respostas a dois itens baseados em escalas de resposta de 7 pontos que variam entre "nada" e "muito".

N1. Até que ponto o sr./sra. diria que o governo federal atual combate a pobreza.

N12. Até que ponto o sr./sra. diria que o governo federal atual combate o desemprego.

Experiências com corrupção são construídas como uma escala composta de itens sobre a vitimização à corrupção, com alternativas de resposta "sim" ou "não", exceto quando explicitado de outra forma:

EXC2. No último ano algum agente de polícia pediu ao sr./sra. uma propina (ou suborno)?

EXC6. No último ano um funcionário público solicitou ao sr./sra. uma propina (ou suborno)? 
EXC13. No último ano no seu trabalho, alguém solicitou alguma propina (suborno)?

EXC14. O sr./sra. teve que pagar alguma propina (suborno) aos juízes?

EXC15. Para ser atendido em um hospital ou em um posto de saúde, o sr./sra. teve que pagar alguma propina (suborno)?

EXC16. Na escola ou colégio, o sr./sra. teve que pagar alguma propina (suborno)?

EXC7. Considerando sua experiência ou o que ouviu falar dos funcionários públicos, a corrupção dos funcionários públicos está... ? [LER] (1) Muito comum (2) Algo comum (3) Pouco comum (4) Nada comum (8) NS/NR

Vitimização por crime foi operacionada por meio de itens com respostas "sim" ou "não":

VIC1. Agora mudando de assunto, o sr./sra. foi vítima de algum ato de deliquência (assalto, roubo, sequestro relâmpago, etc.) nos últimos doze meses?

A participação em protestos políticos é baseada nos seguintes itens:

PROT1. Alguma vez na sua vida o sr./sra. participou de manifestação ou protesto público? Participou algumas vezes, quase nunca ou nunca?

Eu uso diversas variáveis para medir a visão do cidadão sobre as instituições de democracia representativa tradicionais. No que se refere a partidos políticos, uso dois itens. O primeiro tem como alternativa de resposta "sim" ou "não" e o segundo apresenta uma escala de sete pontos que varia de "nada" a "muito".

VB10. Atualmente o sr./sra. simpatiza com algum partido político?

B21. Até que ponto o sr./sra. tem confiança nos partidos políticos?

Para medir as perspectivas sobre o congresso, emprego dois itens. O segundo item, B13, utiliza o mesmo estilo de alternativa de reposta do B21.

M2. Falando do Congresso Nacional e pensando em todos os deputados, sem levar em consideração os partidos políticos a que pertencem, o sr./sra. pensa que os deputados estão fazendo um trabalho muito bom, bom, nem bom nem mal, mal ou muito mal? (1) Muito bom (2) Bom (3) Nem bom, nem mal (regular) (4) Mal (5) Muito mal (péssimo)

B13. Até que ponto o sr./sra. tem confiança no Congresso Nacional?

A última variável é um índice de confiança nas principais instituições democráticas, que será aqui usada para operacionalizar o apoio ao regime 
democrático, e é composta por três itens além do B13, que apresentam as mesmas alternativas de resposta.

B10A. Até que ponto o sr./sra. tem confiança na justiça?

B11. Até que ponto o sr./sra. tem confiança na Justiça Eleitoral?

B14. Até que ponto o sr./sra. tem confiança no Governo Federal?

Todos estes itens têm a vantagem de serem diretamente relacionados a fatores de observação concretos. Não há itens sobre o apoio à democracia ou conceitos mais difusos, que tendem a criar questionamentos sobre a acurácia com que o entrevistado reporta suas opiniões sobre eles (Knight 2001). Ou seja, não há itens abstratos ou complexos em demasia que causem problemas para serem respondidos. Além disso, mesmo que o interesse recaia sobre as tendências centrais nesses países, também se inclui na análise medidas de discordância dos entrevistados e de dispersão das opiniões representadas pelos intervalos de confiança nos gráficos abaixo. Por este motivo, não se presume que estas opiniões sejam dominantes, se quer majoritárias em cada país isoladamente: testa-se por isso considerando o intervalo de confiança (Knight 2001).

\section{Análise}

$\mathrm{Na}$ análise que segue, são apresentadas evidências de visões do público sobre questões que podem estar associadas a crises democráticas. Países que passaram por crises devem ser agrupados de acordo com as hipóteses apresentadas anteriormente: assim, deve haver um processo de "clustering", aglomeração de países em grupos que passaram por crises e grupos que não atravessaram crises.

Em teoria, não foi definido um modelo que explica crises, mas um que se baseia em como fatores covariam e estão associados com crises democráticas. Qualquer modelo de crise democrática ou instabilidade de regime deve ser necessariamente mais complexo que o discutido aqui, incluindo explicações sistêmicas e contextuais com a utilização de dados de várias fontes e tipos diferentes. Mas, isso é tarefa para o futuro.

Começamos nossa discussão dos resultados com a análise das percepções sobre performance econômica nos países da região. A figura 1 não indica qualquer padrão claro que diferencie países que atravessaram crises - marcados com a cor mais escura no gráfico - de países que não atravessaram crises. ${ }^{5}$ Há

${ }^{5}$ Incluí o caso do México entre os países que atravessaram crises por conta de sua profunda instabilidade eleitoral em 2006. 
FIGURA 1

Avaliações do desempenho econômico do governo nas Américas - 2008

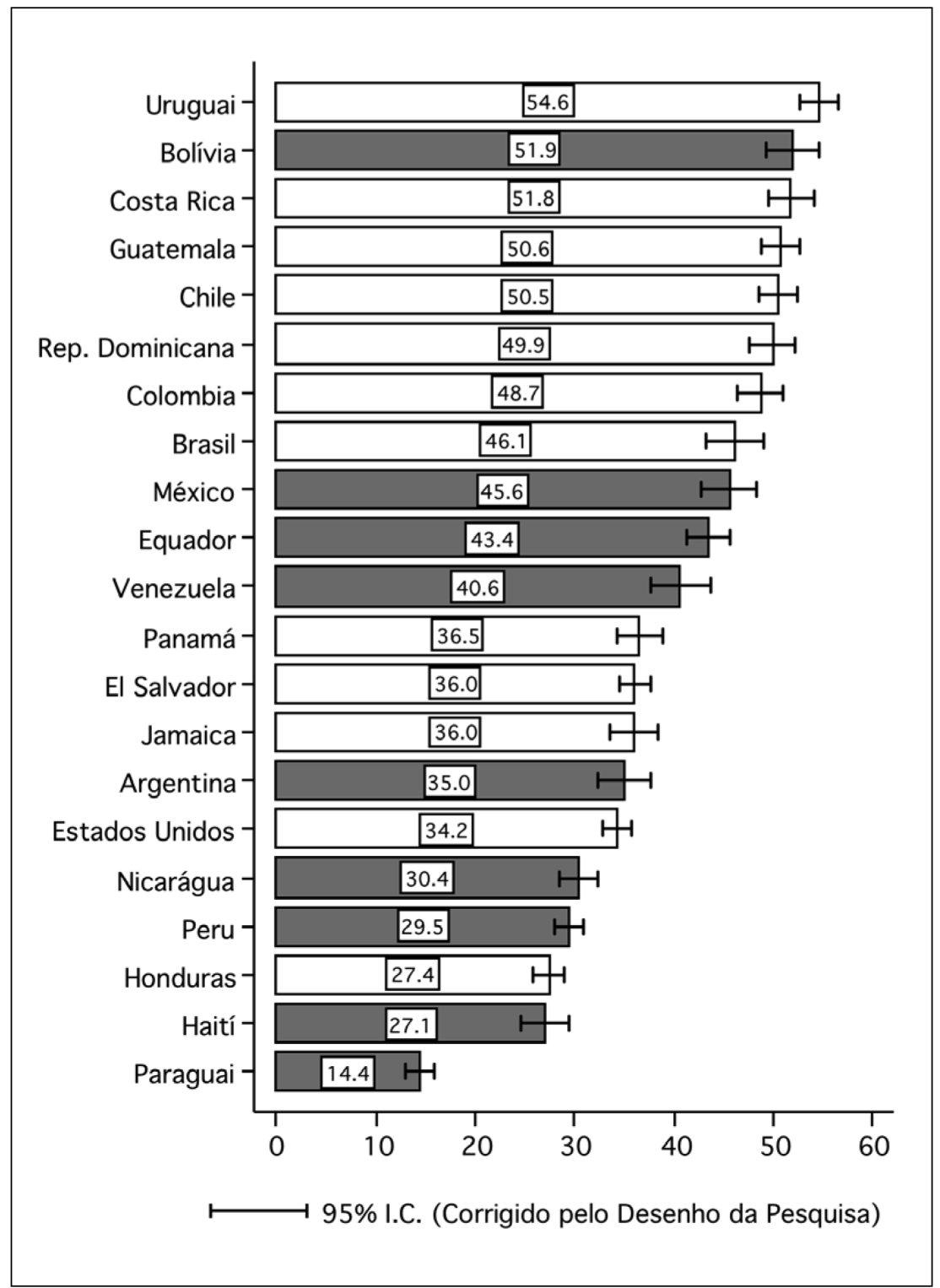

FONTE: Americas Barometer by LAPOP. 
FIGURA 2

Vitimização por Corrupção nas Américas - 2008

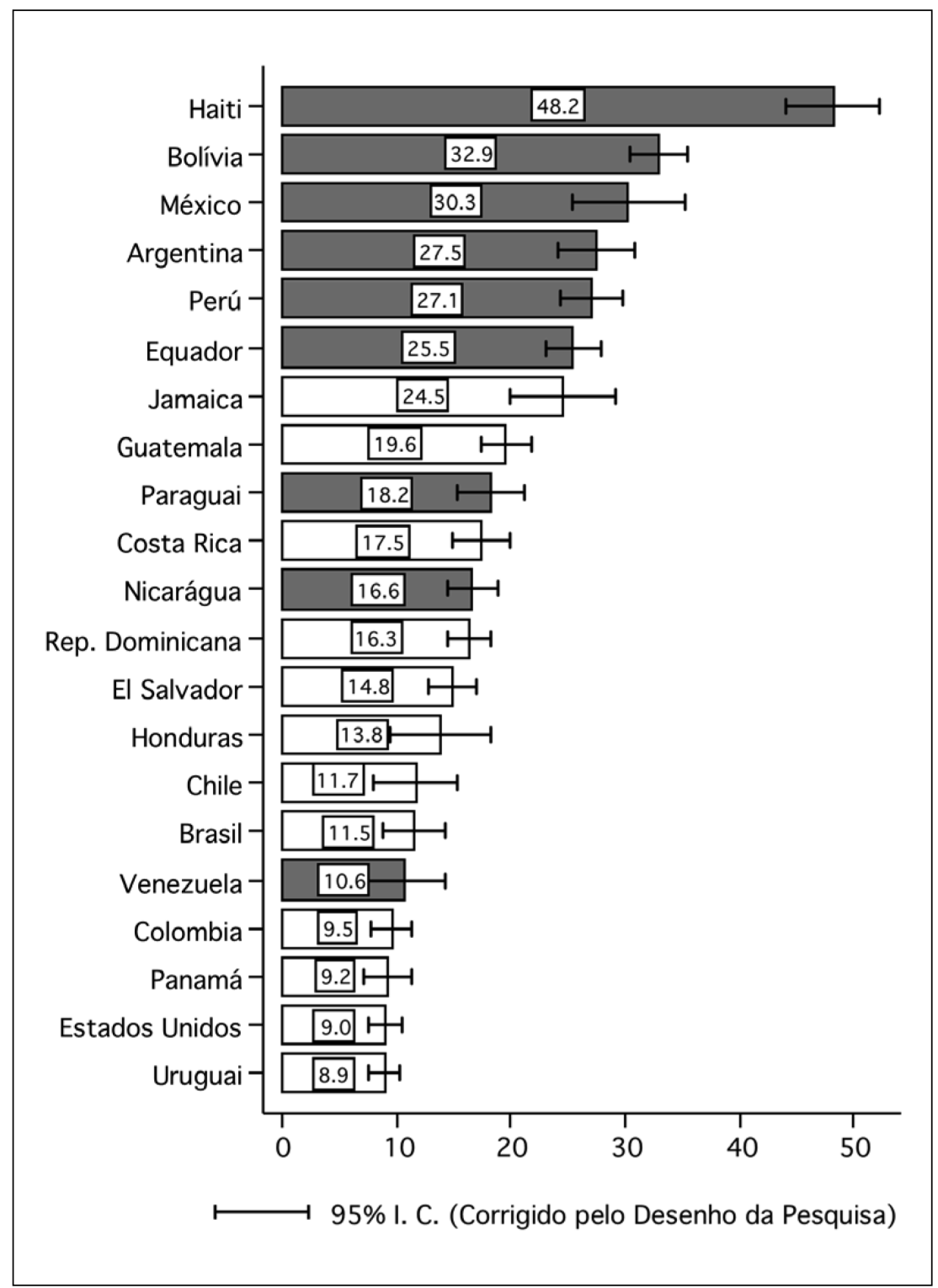

FONTE: Americas Barometer by LAPOP. 
alguma aglomeração de países em crise nos níveis mais baixos de avaliação do desempenho econômico do governo, mas em padrão não tão claro como o que será observado em outras variáveis. Assim, esse ponto inicial confirma a visão de Boniface em que não há uma relação clara entre situação econômica e crise democrática.

A figura 2 apresenta um quadro distinto. Com relação à experiências com corrupção, há uma clara aglutinação de países que atravessaram crise nos pontos mais altos da escala, confirmando a expectativa de que vitimização e percepção sobre a corrupção estão claramente associadas à existência de crises democráticas.

Em seguida, discutimos a hipótese de que vitimização por crime é outro fator associado à crises democráticas. Os resultados não são evidentes nesse caso, como foram na questão da corrupção, o que indica uma baixa capacidade dessa variável de distinguir os países que enfrentaram crises dos demais. Aparentemente, os problemas de segurança pública perpassam todos os países da região (figura 3).

Corrupção, então, está mais fortemente relacionada com crises da democracia do que crime e percepções sobre a economia. E quanto à participação em protesto políticos? Há maior engajamento em protestos nos países que atravessaram crises? Os resultados apresentados na figura 4 não deixam dúvidas de que, mesmo passadas as crises, o engajamento da cidadania em movimentos de protesto continua alta nos países que vivenciaram turbulência política recente. Assim, as crises democráticas do passado, tão claramente baseadas e nutridas por protestos políticos, não eliminaram os problemas e a incidência de engajamento em protestos continua elevada entra a população desses países. Ou seja, a continuação de altos níveis de percepção e vitimização por corrupção, ao lado de uma continuada presença popular em protestos de rua continuam presentes nos países que atravessaram crises democráticas no passado recente.

Finalmente passamos para a discussão sobre indicadores de participação, avaliação e confiança em instituições tradicionais da democracia representativa. Afinal, para Hagopian, Mainwaring e colaboradores, na essência da instabilidade democrática na região Andina está a crise das instituições tradicionais de representação de interesses. As figuras 5 e 6 apresentam dados sobre atitudes frente aos partidos políticos. Fica claro que ainda em 2008, mesmo passadas as crises, os cidadãos dos países que enfrentaram essas instabilidades em seus regimes no passado continuam descrentes dos partidos políticos, embora indiquem alguma identificação com partidos políticos. Ou seja, a crise de representatividade não foi contornada após as crises.

Em trabalhos futuros iremos explorar como essa identificação com partidos políticos pode resultar em cicatrizes mais profundas deixadas pelas crises 
FIGURA 3

Vitimização por crime nas Américas - 2008

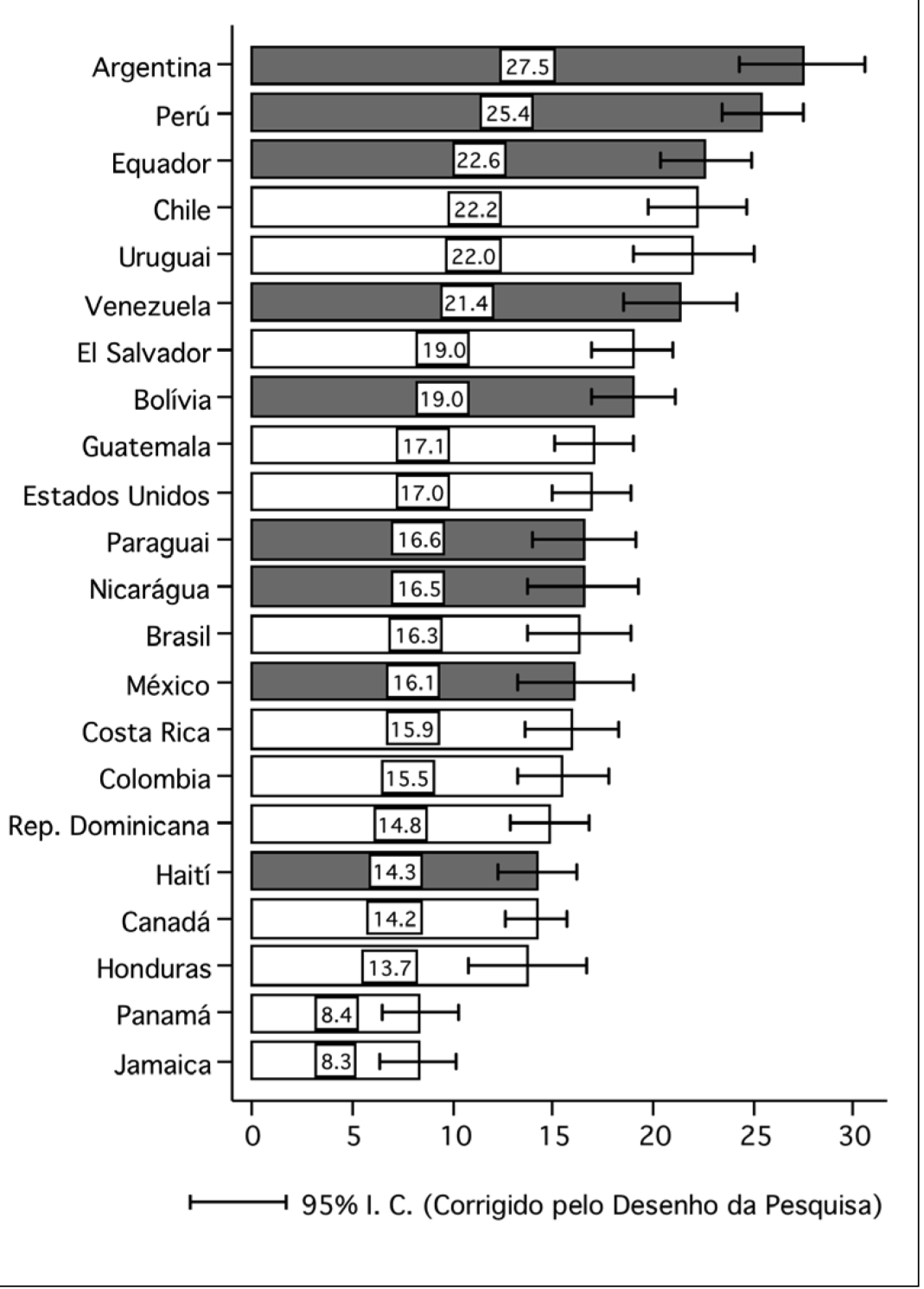

FONTE: Americas Barometer by LAPOP. 
FIGURA 4

Participação em protestos políticos nas Américas - 2008

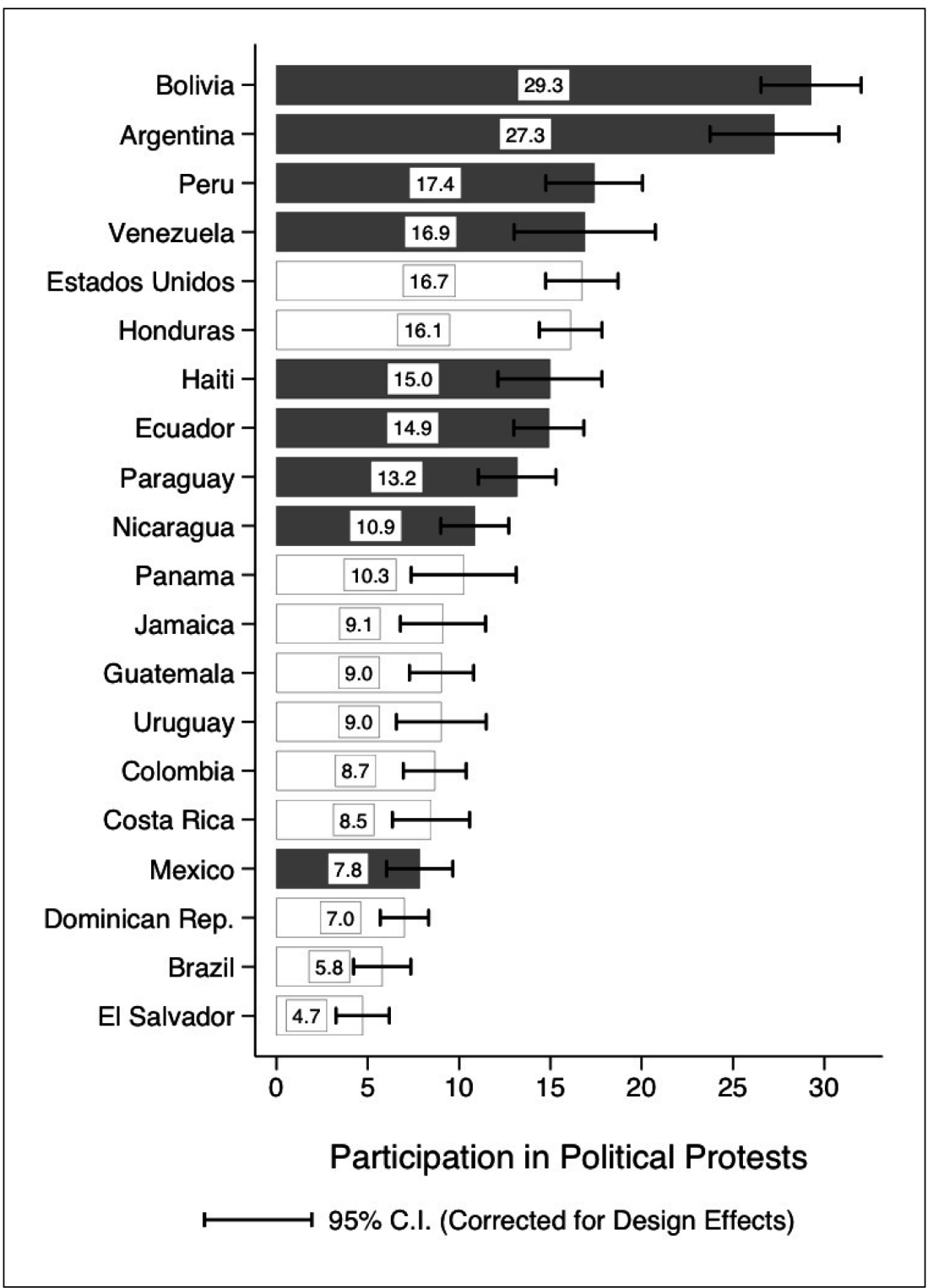

SOURCE: Americas Barometer by LAPOP. 
FIGURA 5

Confiança em partidos políticos nas Américas - 2008

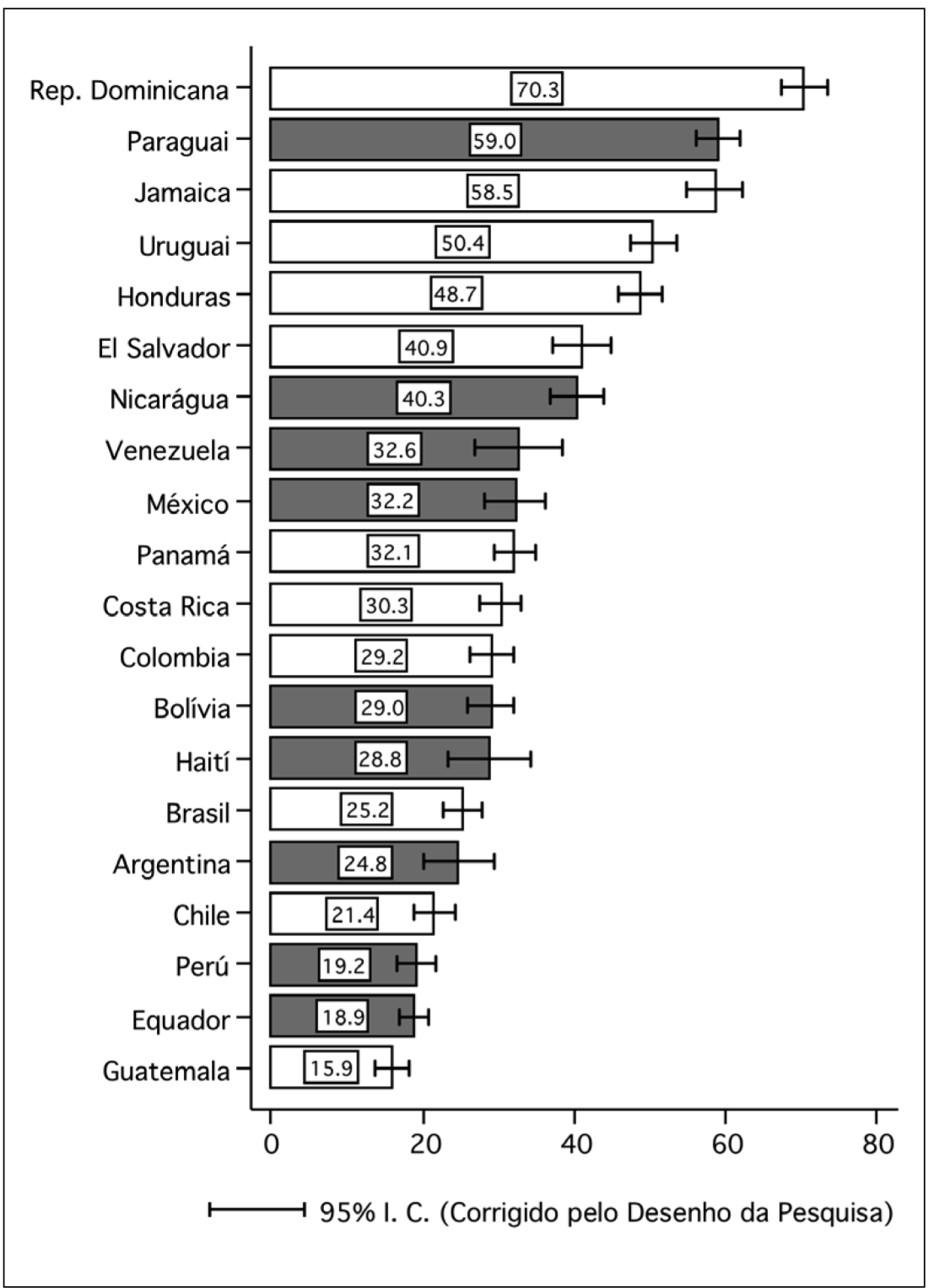

FONTE: Americas Barometer by LAPOP. 
FIGURA 6

Identificação com partidos políticos nas Américas - 2008

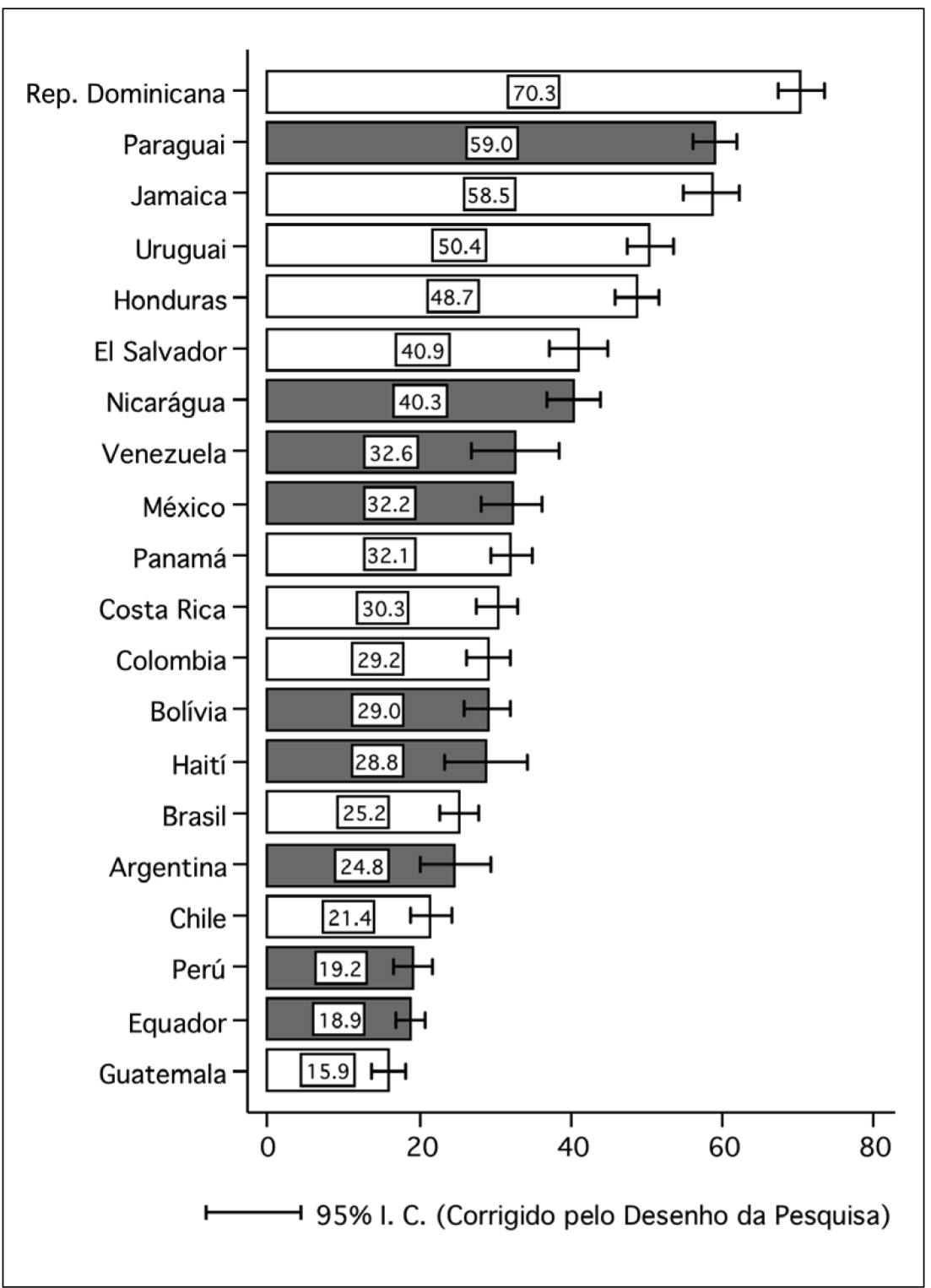

FONTE: Americas Barometer by LAPOP. 
dentre os membros de partidos da oposição aos regimes em vigor e que implementaram reformas amplas das regras democráticas. Mas, novamente, esse tema específico é parte da agenda mais ampla de pesquisa em que este primeiro trabalho se insere e será discutido aprofundadamente no futuro.

Também de forma semelhante, países que tiveram crises democráticas recentes também se aglomeram nos níveis mais baixos de confiança no Congresso e avaliações de seus representantes no poder legislativo. Aqui também vemos que o rescaldo das crises não foi uma melhora na avaliação das instituições (figuras 7-8).

Finalmente, em relação ao índice geral de legitimidade das instituições democráticas, vemos os países que atravessaram crises também nos níveis mais baixos. Ou seja, parecem haver fatores mais sistêmicos e enraizados nesses sistemas políticos que o diferenciam daqueles que não atravessaram crises. Mais importante ainda, o saldo das crises não foi uma reversão de padrões anteriores e uma caminhada no sentido de melhora da situação anterior.

A simples inspeção visual dos gráficos acima indicam que corrupção e protestos políticos tem sido características definidoras de países que atravessaram crises democráticas recentes. As crises do passado não contribuíram para possivelmente alterar esses fatores, supondo que eles já existiam antes, o que só poderemos afirmar de forma contundente com dados comparados no tempo. De qualquer forma, se levarmos em consideração os trabalhos de Hoschestetler/Edwards e de Pérez-Liñan, que se baseiam em dados do passado recente e que apontam para esses dois fatores como já presentes antes das crises, o que se pode afirmar é que após as crises, esses dois elementos continuam relevantes nos países que vivenciaram turbulência política. Também fica claro que esses países continuam imersos em profundas crises de representatividade de suas instituições políticas tradicionais. Ou seja, não houve, com raras exceções, uma recuperação do apoio ao sistema democrático após as crises.

A tabela 1 abaixo apresenta coeficientes de associação entre uma variável que indica se o país atravessou crises e as diferentes medidas discutidas acima. As associações mais claras são entre experiências com corrupção e participação em protestos políticos, confirmando a análise acima. A combinação desses dois fatores parece ser explosiva para sistemas políticos.

\section{Conclusões}

Os resultados acima indicam que países que atravessaram crises da democracia no passado recente continuam se diferenciando dos demais países em fatores que são tidos como centrais para explicar essas crises. Corrupção, engajamento em protestos políticos, baixa avaliação das instituições democráticas 
FIGURA 7

Confiança no congresso nas Américas - 2008

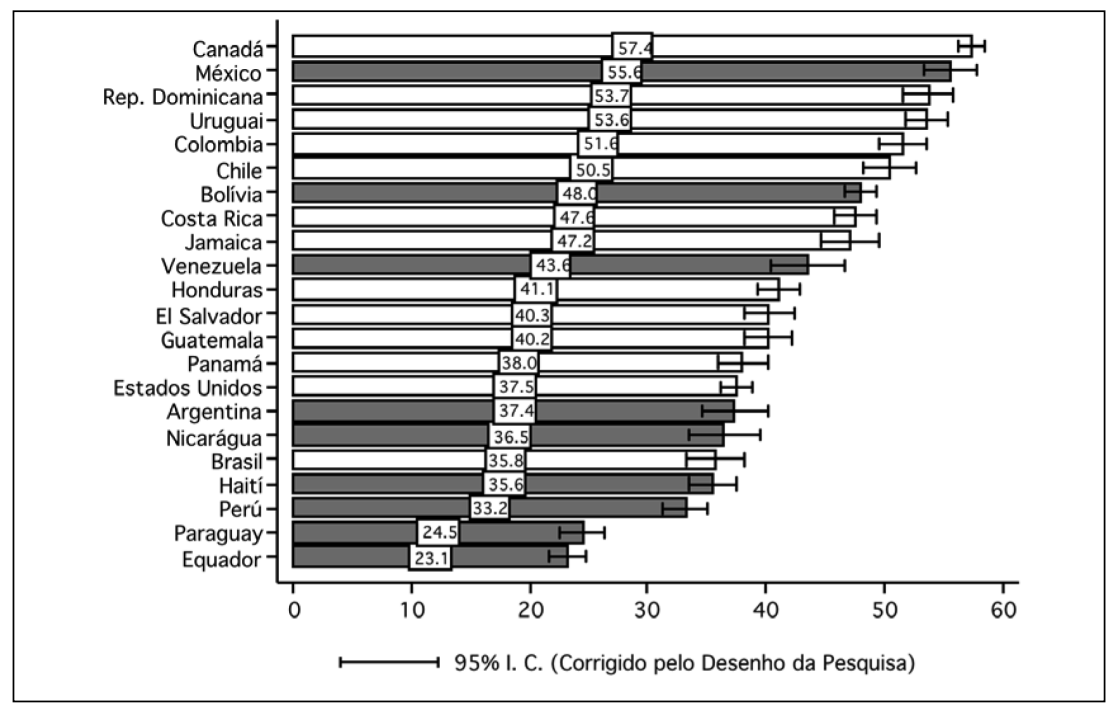

FONTE: Americas Barometer by LAPOP.

FIGURA 8

Avaliação de representantes eleitos no Congresso nas Américas - 2008

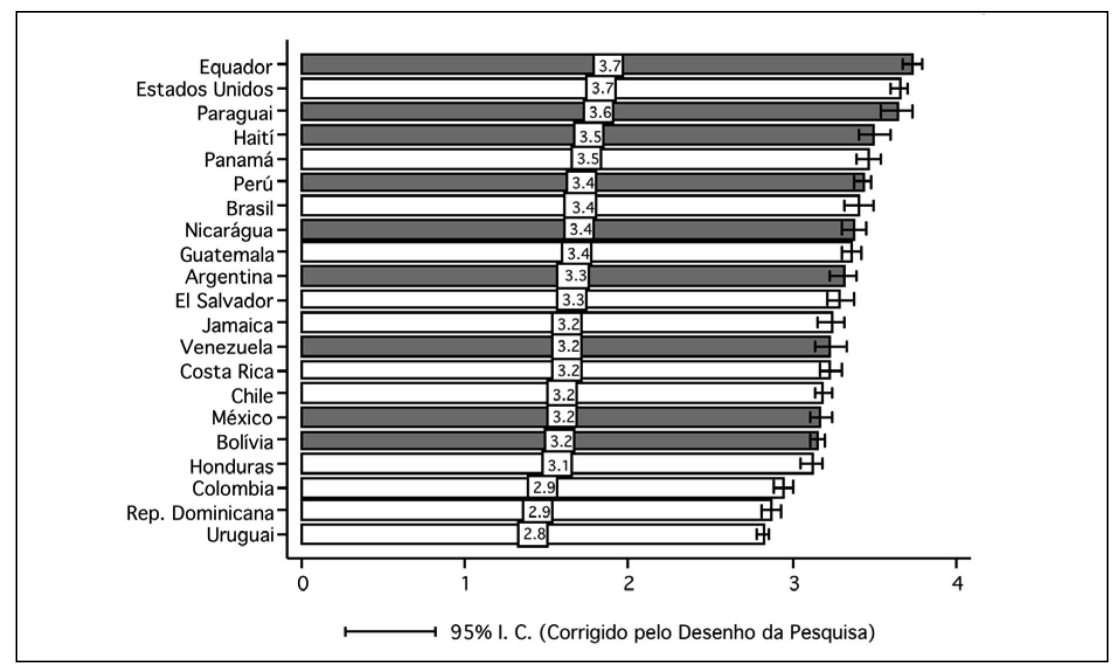

FONTE: Americas Barometer by LAPOP. 
TABELA 1

Coeficientes Gamma para associação entre variáveis selecionadas e crises democráticas

\begin{tabular}{|l|c|}
\hline Variáveis & Coeficiente Gamma \\
\hline Performance econômica do Governo & -0.13 \\
\hline Experiências com corrupção & 0.43 \\
\hline Vitimização por crime & 0.13 \\
\hline Participação em protestos políticos & 0.42 \\
\hline Identificação com partidos políticos & -0.20 \\
\hline Confiança em oartidos oolíticos & -0.18 \\
\hline Avaliação de representantes no poder legislativo & -0.13 \\
\hline Confiança no Congresso & -0.20 \\
\hline Legitimidade das instituições democráticas & $-0.18^{*}$ \\
\hline
\end{tabular}

* Usamos nesse caso um coeficiente de correlação Pearson.

representativas continuam diferenciando os regimes que atravessaram turbulência política na última década. Assim, não se pode afirmar que todo o processo de instabilidade, alimentado pela insatisfação da população com a qualidade da representação democrática na região, resultou em regimes melhores, que solucionaram as crises com medidas eficientes e que atacavam, de fato, os fatores motivadores dessas mesmas crises. É possível inclusive especular que as crises da democracia podem ter gerado cicatrizes em grupos específicos, os que perderam nos conflitos ou nos processos de reforma do Estado subsequentes, que resultam em ainda maior distanciamento desses grupos do sistema política e a formação de clivagens políticas ainda mais intensas e conflitivas. Essa combinação de fatores, portanto, pode colocar em risco o processo de consolidação da democracia nesses países e facilmente levar esses regimes a caminhos irreversíveis de consolidação da instabilidade como traço definidor. 


\section{Bibliografia:}

Avritzer, Leonardo (2002): Democracy and the Public Space in Latin America. Princeton: Princeton University Press.

Boniface, Dexter (2007): “The OAS's Mixed Record”, em Legler, T./Sharon, F. L./Boniface, D. (eds.): Promoting Democracy in the Americas. Baltimore: The Johns Hopkins University Press, pp. 40-62.

Booth, John/Seligson, Mitchell (2009): The Legitimacy Puzzle in Latin America: Political Support and Democracy in Eight Nations. Cambridge: Cambridge University Press.

DiAmond, Larry/Morlino, Leonardo (eds.) (2004): Assessing the Quality of Democracy. Baltimore: The Johns Hopkins University Press.

Hagopian, Frances/Mainwaring, Scott P. (2005): The Third Wave of Democratization in Latin America: Advances and Setbacks. Cambridge: Cambridge University Press.

HochSTETLER, Kathryn (2008): "Repensando el presidencialismo: desafíos y caídas presidenciales en el Cono Sur“, em: América Latina Hoy, Vol. 49 Nuevas Formas de Inestabilidad Política, pp. 51-72.

HochstetLer, Kathryn/Edwards, Margaret (2009): "Failed Presidencies: Identifying and Explaining a South American Anomaly“, em: Journal of Politics in Latin America, 1:2, 31-57.

Hoffman, Kelly/Centeno, Miguel Angel (2003): “The Lopsided Continent: Inequality in Latin America", em: Annual Review of Sociology, 29, pp. 363-390.

Huntington, Samuel P. (1968): Political Order in Changing Societies. New Haven/ London: Yale University Press.

KNIGHT, Alan (2001): "Polls, Political Culture and Democracy: A Heritical Historical Look“, em: Camp, Roderic (ed.): Citizen Views of Democracy in Latin America. Pittsburgh: University of Pittsburgh Press, pp. 223-242.

Llanos, Mariana/Marsteintredet, Leiv (2010): Presidential Breakdowns in Latin America: Causes and Outcomes of Executive Instability in Developing Democracies. New York: Palgrave Macmillan.

LinZ, Juan J. (1978): The Breakdown of Democratic Regimes: Crisis, Breakdown, and Reequilibration. Baltimore/London: The Johns Hopkins University Press.

MaINwARING, Scott (2006): "The Crisis of Representation in the Andes", em: Journal of Democracy, 17:3, pp. 13-27.

Mainwaring, Scott/Bejarano, Ana María/Leongómez, Eduardo Pizarro (2006): The Crisis of Democratic Representation in the Andes. Stanford: Stanford University Press.

Mainwaring, Scott/O'Donnell, Guillermo/Valenzuela, J. Samuel (1992): Issues in Democratic Consolidation: The New South American Democracies in Comparative Perspective. Notre Dame: Published for the Helen Kellogg Institute for International Studies by University of Notre Dame Press.

MARSTEINTREDET, Leiv (2008): "Las consecuencias sobre el régimen de las interrupciones presidenciales en América Latina“, em: América Latina Hoy, Vol. 49 Nuevas Formas de Inestabilidad Política, pp. 31-50. 
MoIsés, José Álvaro (1995): Os Brasileiros e a Democracia: Bases Sócio-Politicas da Legitimidade Democrática. São Paulo: Editora Ática.

Perez-Liñan, Anibal (2007): Presidential Impeachment and the New Political Instability in Latin America. Cambridge: Cambridge University Press.

- (2008): "Instituciones, coaliciones callejeras e inestabilidad política: perspectivas teóricas sobre las crisis presidenciales“, em: América Latina Hoy, Vol. 49 Nuevas Formas de Inestabilidad Política, pp. 105-126.

Portes, Alejandro/Hoffman, Kelly (2003): "Latin American Class Structures: Their Composition and Change during the Neoliberal Era“", Latin American Research Review, 38:1, pp. 41-82.

PrZeworski, Adam (1986): "Some Problems in the Study of the Transition to Democracy“, em: O’Donnell, G./Schmitter, P./Whitehead, L. (eds.): Transitions from Authoritarian Rule: Comparative Perspectives. Baltimore/London: The Johns Hopkins University Press, pp. 47-63.

REIs, Fábio Wanderley/O’Donnell, Guillermo (1988): A Democracia no Brasil : dilemas e perspectivas. São Paulo: Vértice.

Rennó, Lucio/Smith, Amy E./Layton, Matthew L./Pereira, Frederico B. (2011): Legitimidade e Qualidade da Democracia no Brasil: Uma Visão da Cidadania. São Paulo: Intermeios.

Seligson, Mitchell (2007): "The Rise of Populism and the Left in Latin America“, em: Journal of Democracy, 18:3, pp. 81-95.

Stepan, Alfred (1989): Democratizing Brazil: Problems of Transition and Consolidation. New York/Oxford: Oxford University Press.

ZAKARIA, Fareed (1997):"The Rise of Illiberal Democracy“, em: Foreign Affairs, 76, pp. 22-43. 